Portland State University

PDXScholar

\title{
Measurement of the Cross-Sectional Area of the Nasal Passages of Nine Species of Modern Odontoceti with Implications for Comparative Physiology and the Paleophysiology of the Dinosauria
}

Eric Paul Katz

Portland State University

Follow this and additional works at: https://pdxscholar.library.pdx.edu/open_access_etds

Part of the Biology Commons

Let us know how access to this document benefits you.

\section{Recommended Citation}

Katz, Eric Paul, "Measurement of the Cross-Sectional Area of the Nasal Passages of Nine Species of Modern Odontoceti with Implications for Comparative Physiology and the Paleophysiology of the Dinosauria" (1999). Dissertations and Theses. Paper 2247.

https://doi.org/10.15760/etd.2244

This Thesis is brought to you for free and open access. It has been accepted for inclusion in Dissertations and Theses by an authorized administrator of PDXScholar. Please contact us if we can make this document more accessible: pdxscholar@pdx.edu. 
THESIS APPROVAL

The abstract and thesis of Eric Paul Katz for the Master of Science in Biology were presented March 5, 1999, and accepted by the thesis committee and the department.

COMMITTEE APPROVALS:

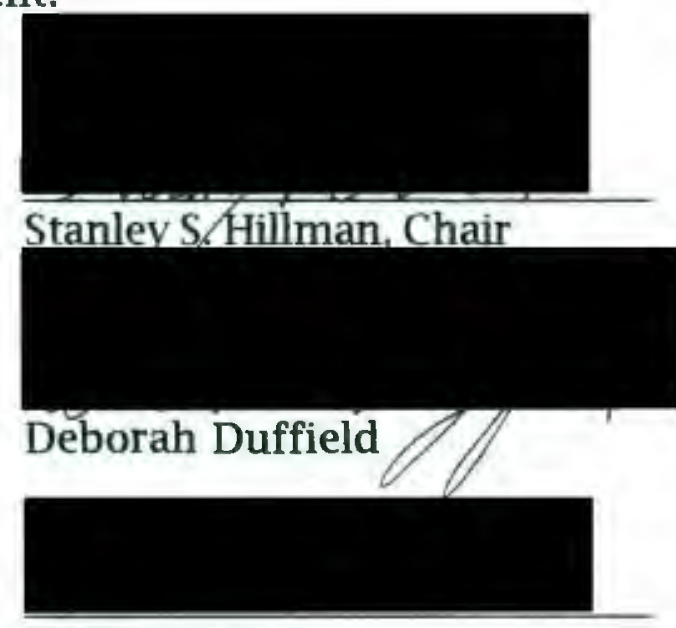

Richard Forbes

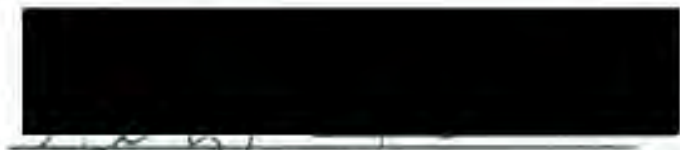

Gary Brodbwicz, Representative of the Office of Graduate Studies

DEPARTMENT APPROVAL:

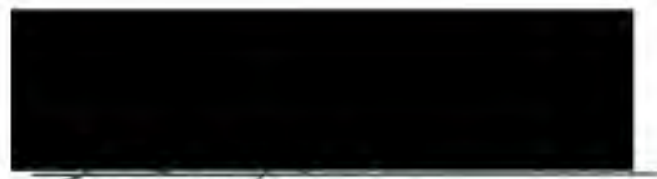

Stanley S. Millman, Chair Department of Biology 
An abstract of the thesis of Eric Paul Katz for the Master of Science in Biology presented March 5, 1996.

Title: Measurement of the Cross-Sectional Area of the Nasal Passages of Nine Species of Modern Odontoceti, With Implications for Comparative Physiology and the Paleophysiology of the Dinosauria.

In search of evidence for or against the endothermic dinosaur hypothesis, a recent study by Ruben et al. (1996) revealed that endotherms tend to have larger nasal cross-sectional areas than ectotherms of the same mass. The reason offered for this observation was that larger nasal passages are needed to house the complex respiratory turbinates possessed by endotherms. Whales were excluded from the study on the grounds that they have no nasal turbinates. In the present study, the cross-sectional area of the nasal passages of nine species of Odontoceti were measured by the use of latex casts. The regression of log cross-sectional area vs. log mass yielded the same line for the whales of the current study as for the endotherms of the previous study. Alternative 
explanations for the large nasal cross-sectional area of endotherms are sought. 
MEASUREMENT OF THE CROSS-SECTIONAL AREA OF THE NASAL

PASSAGES OF NINE SPECIES OF MODERN ODONTOCETI

WITH IMPLICATIONS FOR COMPARATIVE PHYSIOLOGY

AND THE PALEOPHYSIOLOGY

OF THE DINOSAURIA

by

ERIC PAUL KATZ

A thesis submitted in partial fulfillment of the

requirements for the degree of

\author{
MASTER OF SCIENCE \\ in \\ BIOLOGY
}

Portland State University

1999 


\section{Acknowledgments}

I am grateful to Dr. Duffield, Dr. Hillman, Dr. Forbes and Dr. Bevers for critical reviews of the early drafts of this paper, and numerous ideas along the way. Thanks especially to Stan Hillman for conceiving of the project. Thanks are also due to Dr. Duffield, Dr. Hillman, and Dr. Forbes for the use of their skulls and equipment. Thanks to the library staff at the Hatfield Marine Science Center. Although no grant money was directly used for this thesis, this work could not have been done without the employment from the PSU department of Biology and Stan Hillman, and financial support from my parents.

\section{Dedications}

This thesis is dedicated to Dr. Forbes, Dr. Duffield and especially Stan Hillman, who helped me to incubate my ideas, and who kept me going when times got rough. Thanks to my parents for their unflagging emotional support. 
ACKNOWLEDGMENTS............................

TABLE OF CONTENTS............................

LIST OF TABLES....................................

LIST OF FIGURES. ............................ . . . . .

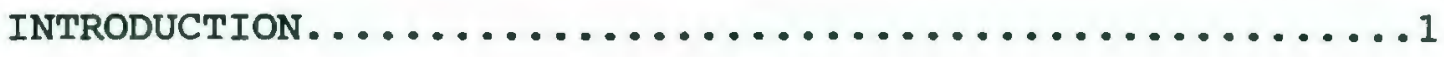

MATERIALS AND METHODS............................ 17

RESULTS................................... 26

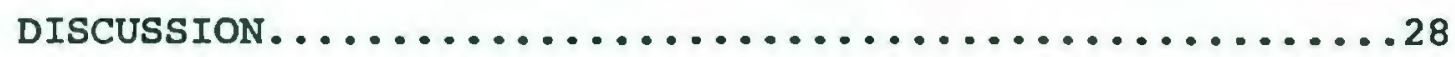

CONCLUSIONS.................................... 34

LIST OF REFERENCES........................... 38 


\section{LIST OF TABLES}

Tables

Page

1. Table 1. Cross Sectional Areas $\left(A_{n}\right)$ in $\mathrm{cm}^{2}$, and Masses (Minimum, Maximum and Intermediate) in $\mathrm{kg} \ldots \ldots \ldots 35$ 


\section{LIST OF FIGURES}

Figures page

1. Figure 1. The Regression Line of $\log A_{n}$ vs. $\log B o d y$

Mass, Compared to $\log A_{\operatorname{mid}}$ vs, $\log$ Body Mass......36

2. Figure 2. The Regression Line of $\log A_{n}$ vs. $\log$ Body

Mass, Compared to the log Cross-Sectional Area vs.

log Body Mass Regressions Found by Ruben et al (1996)

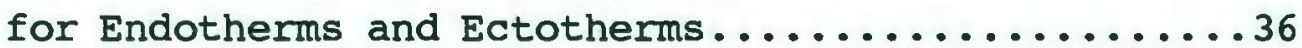

3. Figure 3a. Cross-Sectional Area vs. Maximum Body

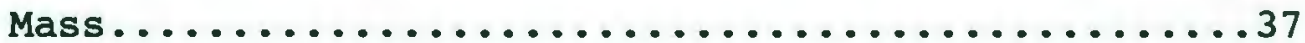

4. Figure 3b. Cross-Sectional Area vs. Minimum Body

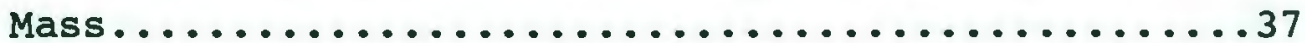




\section{Introduction}

The status of dinosaurs as torpid, cold-blooded animals has been under fire from a growing host of specialists since at least 1968. Reid (1987) considered the argument over whether dinosaurs were endothermic to have been started either by Robert Bakker (1968) or by John Ostrom (1969). Both Bakker (1968) and Ostrom (1969) used the upright posture of dinosaurs to support their respective conclusions, which were quite different. Ostrom's aim was not to establish dinosaurian endothermy, but simply to question the assumption of dinosaurian ectothermy in paleoclimatology. Although a section of Ostrom's paper is devoted to the question of dinosaurian endothermy, most of it deals with the question of what evidence can and cannot be used as valid paleoclimatic indicators. Previously it had been assumed that the presence of dinosaurs in a fauna indicated a warm climate, because dinosaurs were thought to be ectotherms, and therefore required warm climates in order to function. Ostrom argued that if the thermal physiology of an extinct animal is even in question, it cannot be used as an indicator of any particular climate. Dinosaurs constituted for Ostrom only one example of a taxon whose physiology was in doubt. This example was inspired by a paper in 
which Russel (1965) argued that the extinction of the dinosaurs would be better understood if they were endothermic.

Bakker's paper (1968) was also not about endothermy. Bakker originally cited the dinosaurs' upright stance and presumed agility as their principle advantages over the late Permian synapsids that they displaced. Bakker's central thesis was not that dinosaurs were endotherms, but that they were quick and agile and that these abilities aided their success over the therapsids.

The two arguments seem to have been joined when Bakker (1971) detailed his theory of the relationship between dinosaurian physiology and the origin of mammals. By this time, Bakker's premise had changed, and he asserted that dinosaurs must have been endothermic or they would not have prevented mammals from radiating into their modern niches. By way of evidence, he described the limbs of several species of reptiles, mammals and birds, both extant and extinct, and attempted to draw a positive correlation between endothermy and upright stance. Much of Bakker's paper was devoted to the description of the posture and musculature of these reptiles mammals and birds, but his two main points were that upright posture seems to be correlated with high body temperature and that upright posture requires less muscular activity in the act of support. Bakker demonstrated that no modern 
ectotherm has an upright posture (he calls the posture of the chameleon semi-erect), but did not attempt to show that this correlation must also hold for all fossil species as well.

Bakker (1972) derived a formula for the "maximal" speed of an animal of a given mass, assuming ectothermic physiology. From this formula, he tried to show that maximal running speed of an ectotherm is far slower that one would predict from the morphology of a theropod's legs. The formula was designed to predict the maximal speed that is aerobically sustainable, but not all activity needs to be aerobic. Thus, an ectotherm might be able to run at higher speeds than the formula predicts, if only for limited periods of time.

Two other arguments were developed by Bakker (1972), one from the energy budget of a community and one from bone histology. The argument from community ecology began with the assertion that communities dominated by endothermic predators have fewer predators than do communities in which the top predators are ectotherms. Bakker supported this claim by citing data that cheetahs (Acinomyx jubatus), wild dogs (Lycaon pictus) and tigers (Panthera tigris) (all undoubted endotherms) eat more, relative to body weight, per month than do komodo dragons (Varanus komodoensis), which are ectotherms (Auffenberg 1971, Schaller 1968, 
Wright 1960). This phenomenon was expressed in terms of the ratio of secondary productivity to standing crop (SP/SC). This ratio is an order of magnitude higher when the top carnivore is an ectotherm than when it is an endotherm, because endotherms have a higher resting metabolism than ectotherms do, and consequently use more energy simply for thermoregulation. Bakker estimates that the SP/SC ratio for late Cretaceous Canadian dinosaur communities was more like that seen when there is an endothermic top predator than when there is an ectothermic top predator.

Bakker's third argument (1972) is supported mostly by the data of Enlow and Brown $(1957,1958)$, who showed that large mammals tend to have Haversian bone, whereas reptiles tend to have nearly avascular bone. Bakker explained this observation in terms of rapid turnover of calcium phosphate in endotherms, and concluded that laminar haversian bone indicates endothermy. The vascular bone of some prosauropod and sauropod dinosaurs (Currey 1962, Tarlo and Mercer 1968) suggested that they were endothermic. Bakker also states, "All the dinosaurs which I have investigated display densely Haversian or laminar bone or both."

Bakker's central arguments had been laid out by 1972. It is critical to the understanding of the development of these arguments that nowhere in the Bakker and Ostrom articles does 
either distinguish between the terms homeothermy and endothermy. More importantly, there is a tacit assumption in Bakker's papers that high activity rates are correlated with endothermy and (presumably) a high $\mathrm{VO}_{2 \text { max }}$. These omissions have lead to great confusion, even after they were discovered.

A brief review of the basic terminology of metabolic physiology is in order. $\dot{\mathrm{V}}_{2 \max }$ is the maximal rate at which oxygen can be transported to the cells from the ambient air for a given animal. It is usually associated with high rates of activity (such as running). $\dot{\mathrm{VO}}_{2 \text { rest }}$ is the minimal rate at which oxygen is transported, as above, and is a measure of the "idle" rate of metabolism. An endotherm uses a high $\dot{\mathrm{VO}}_{2 \text { rest }}$ to maintain a constant body temperature. The term homeotherm is more general, and applies to any animal that maintains a constant body temperature, regardless of means. An ectotherm is an animal is an animal that gains the majority of its heat from external sources, but may or may not be a homeotherm. If it is not a homeotherm, it does not regulate its temperature at all, and is called a poikilotherm. Finally, aerobic capacity is the maximal capacity to do work using aerobic metabolism, while anaerobic capacity is the maximal ability to do work without oxygen (i.e. with glycolytic metabolism only). Endotherms often have high aerobic capacities. 
Bakker's arguments can be summarized as follows: 1) dinosaurs had an upright and often a cursorial limb-skeleton; therefore they were very active, as are the modern animals that have a similar skeleton. From this, Bakker infered homeothermy or endothermy, without really distinguishing between $\dot{\mathrm{VO}}_{2 \text { rest }}$ and $\dot{\mathrm{VO}}_{2 \max }$ or between aerobic and anaerobic capacity. 2) further support for his position that dinosaurs were endothermic can be found in their community structure and Haversian bone histology. Bakker offered no further evidence that dinosaurs had a high $\dot{\mathrm{V}}_{2 \max }$ presumably because he believed it to be associated with endothermy and requisite for the high activity levels he deduced.

By 1972, the replies to Bakker had started coming in to Evolution. Bennett and Dalzell (1972) wrote a critique of Bakker's logic. They began by asserting that it is "neither logically nor biologically sound" to infer homeothermy simply from upright posture and they required of Bakker either a causal physiological basis or a very strong correlation for this inference. They concluded that Bakker had shown neither, based on their understanding of the energetics of posture and transport, and by their review of the literature in search for correlations between limb length and resting metabolism. Bennett and Dalzell stated that there is no correlation between standard metabolism and limb 
length. Even alligators, they asserted, have many of the hallmarks of an endotherm (elaborate lungs, four-chambered heart, "diaphragm," and a semi-erect stance) and yet have metabolic rates which are "indistinguishable from those of other reptiles (Huggins et al 1971)." Dinosaurs may well have been mass-homeotherms, they assert, but Bakker's conclusions should be accepted only with caution.

Feduccia (1973) wrote a very similar response at about the same time, but it began with a discussion of the terminology involved. Feduccia discussed the differences between an endotherm and a homeotherm. Similarly, Feduccia observed the distinction between an ectotherm and a poikilotherm. He granted that there are gradations between endothermy and ectothermy as well as between poikilothermy and homeothermy. He did not mention the distinction between endothermy and aerobic capacity. Thus, his arguments are limited to discussions of thermal physiology and do not consider the possibility that a dinosaur might have a typically reptilian resting metabolism, but a $\dot{\mathrm{V}}_{2 \max }$ that would be abnormally high for a modern reptile.

Work remained focused on the level and type of thermoregulation that these animals required. If dinosaurs were mass-homeotherms, then it seemed that Bakker's assertion of endothermy would be unjustified. Spotila et al. (1973) created a 
mathematical model to predict the body-temperature fluctuations of a large ectotherm which took into account radiant heat gain and loss, insulation and convection, and temperature-sensitive metabolic heat production. Their model was an iterative one that calculated the net heat flow, determined a body temperature, and then re-calculated the metabolism and net heat flow based on the changes in the heat-dependent parameters. Their results showed that an animal over one meter in diameter would have had a high and nearly constant temperature with or without insulation, given a warm climate and despite a low metabolic rate. Seasonal fluctuations in ambient temperature would have caused seasonal variation in body temperature. The inference is that dinosaurs did not "need" endothermy, because they would have been warm enough for their activities without a large rate of internal heat production.

Thulborn (1973) was first to address the issue of $\mathrm{VO}_{2 \max }$, although he did not mention it by name. Thulborn cited the example of the cheetah and concluded that dinosaurs did not need to have high $\mathrm{VO}_{2 \max }$ to be effective high-speed predators. The cheetah slows down from its top speed within about $15-20$ s, and so must make its catch within this much time. Since lizards are capable of burst activity of about this duration, it follows that an ectothermic dinosaurian predator with a cursorial skeleton should be able to 
attain high speeds and maintain them long enough to catch its prey, provided the prey does not run faster than the prey of a cheetah.

Thulborn (1973) then attacked Bakker's (1971) argument for dinosaurian endothermy based on predator-prey ratios. Bakker's example-species was the Komodo dragon. Bakker claimed that this giant monitor eats half its weight in prey every month, or its full weight in 60 days. Thulborn responded that the estimate of the Komodo dragon's rate of predation was underestimated, and might really be similar to or larger than that of the tiger. Thulborn's (1973) reason for suspecting Bakker's estimate of the dragon's consumption was that there is evidence that the dragon can kill prey up to three times its weight. Unfortunately, Thulborn did not show that the dragon does this regularly, nor did he show that the dragon will feed again after a large meal as soon as it would after a small one. Therefore, Thulborn's estimate of a dragon's monthly appetite seems unsubstantiated.

The replies to Bakker thus far can be summarized as follows: 1) There is no evidence to show that upright stance in an animal is sufficient to conclude that it is endothermic. The correlation between the two is insufficiently rigorous, and because an ectotherm could run fast enough to catch prey, there is no mechanism linking the two factors. The presence of an upright 
stance and cursorial build in dinosaurs is also insufficient to prove that they had a high $\dot{\mathrm{V}}_{2 \max }$ 2) An animal the size of a large dinosaur would be able to maintain a high, constant temperature by mass-homeothermy. Therefore, thermal demands on these large animals would not necessitate endothermy; small dinosaurs are excluded from this analysis. 3) The community ecological evidence depends on the assumption that the ratios of predators to prey is accurately known in many dinosaurian communities.

The papers by Bennett and Dalzell (1972) and Feduccia (1973), taken together, negate the majority of Bakker's arguments, but do not render his major thesis impossible. Thus, the histological evidence (and possibly the ecological) evidence were at this time sufficient to carry the argument forward.

In December of 1974 Armand J. de Ricqles published, for an American audience, a summary of the studies he had been conducting on bone histology in France. His results differed slightly from Bakker's, but supported the contention that dinosaurs were endotherms. De Ricqles' primary observation (1974) was that the histology of all bones can be roughly categorized into either lamellar-zonal or fibro-lamellar types. The lamellar-zonal type is characterized by dense, regular packing of the primary periosteal deposition, with vascularity and growth rings scattered or absent. 
The fibro-lamellar type is characterized by a more "fibrous or woven" appearance, with dense vascularization and blood vessels encased in "finely lammelated, centripetally deposited" primary osteons. In extant tetrapods, the former is associated with low growth rates, as typical of ectotherms, while the latter is associated with high growth rates, as typical of endotherms. This pattern of bone histology seems to be caused directly by the patterns of growth.

De Ricqles concluded that the fibro-lamellar bone-type should be indicative of endothermy in the fossil record, because only endotherms could exhibit such high growth rates. He then reviewed the bone histology and thermal physiology of all the major groups of tetrapods and concluded that dinosaurs and therapsids were endotherms, while the basal synapsids and basal archosaurs were homeothermic and may have been endothermic as well.

A letter to Evolution by Bouvier (1977) was able to disprove Bakker's histological argument (1972), by showing that Haversian bone is not found in all mammals or birds, and that not all reptiles lack Haversian bone. These arguments did not apply to de Ricqles' results, however, because he did not use Haversian systems as the distinguishing factor in his analysis.

Reid (1987) later discredited de Ricqles' technique as a means 
of diagnosing endothermy in the fossil record, but agreed that fibrolamellar bone is related to fast growth. The basis of Reid's analysis was that there are no bone types possessed exclusively by all endotherms or exclusively by all ectotherms. Reid cited several examples against both Bakker's argument about Haversian bone and against de Ricqles' argument about fibro-lamellar bone. However, Reid accepted de Ricqles' initial observation that fibro-lamellar growth occurs only in fast growing animals, and lamellar-zonal bone occurs only in slow-growing animals. Reid agreed with de Ricqles that some dinosaurs must have exhibited more continuously rapid growth than exists in any living reptile, and therefore must have had a physiology different from any living reptile.

De Ricqles' work (1974) and Reid's acceptance of at least part of it, shifted the burden of proof. There was now evidence that the classical view of dinosaurs as cold-blooded and slow was not strictly accurate.

John Ruben et al. (1996) proposed that the cross-sectional area of the nasal passages could be used to estimate the metabolic rate of extinct taxa. Their work is based on the idea, developed by Hillenius $(1992,1994)$, that nasal turbinates are necessary for endothermic metabolism, and so can be used to diagnose it in the fossil record. Hillenius argued that no living ectotherm has 
extensive nasal turbinates (although most exhibit some conchae, the small bony folds in the nasal passages that may be homologous with the extensive respiratory turbinates of endotherms), but that birds and mammals each have independently evolved highly complex turbinates. Hillenius $(1992,1994)$ cited a number of studies (Negus, 1958, Walker et al 1961, Romer and Parsons 1986, Jackson and Schmidt-Nielsen 1964; Schmidt-Neilsen 1969; Collins et al 1971, 1979; Schmidt-Neilsen et al 1981; Schroter and Watkins 1989, 1989) showing that the turbinates decrease the loss of water vapor from the lung, and that the high pulmonary surface areas and ventilation rates of endotherms make the potential water loss very great. Unfortunately, the absence of turbinates in the fossil record does not necessarily imply that the taxon in question had no turbinates. Several modern animals, including birds, have cartilaginous turbinates (Witmer 1995) that could not be expected to fossilize well. Despite Hillenius' argument that some fossil material exhibits bony ridges that indicate turbinates, Witmer concluded that species with an entirely cartilaginous nasal capsule (the structure that houses the turbinates) could not be assessed for turbinates at all. The presence of fossilized turbinates may be deemed sufficient to diagnose endothermy, but cannot be held to be a necessary diagnostic character. 
Ruben et al.'s (1996) response to this setback was to examine the size of the nasal passage of many taxa. Large passages, they argued, indicate the existence of turbinates. The skulls of thirteen modern endotherms (four birds and nine mammals) and nine modern ectotherms (four lizards and five crocodilians) were CAT scanned to measure the cross sectional area of the nasal passages at the midpoint of the passage. Accessory spaces were omitted from the area measured. The areas were then regressed against the masses of the corresponding animals (both log-transformed). The regression line for the endotherms was found to be significantly different from the regression line for the ectotherms in both slope and elevation. Endotherms consistently had larger nasal passages than did ectotherms of similar mass. The cross-sectional areas of three dinosaur taxa (treated similarly) fell near or below the ectotherm line; consequently, Ruben et al. (1996) concluded that the dinosaurs were ectotherms.

One problem with the study done by Ruben et al. (1996), however, was that the diversity of taxa used was limited. The ectothermic taxa were limited to Crocodilus, Varanus and Ctenosaura, representing only three families. The endothermic taxa, although spanning eight families, excluded the Cetacea, whose inclusion was critical because they are the only mammalian group 
that has no turbinates. Notwithstanding the possibility that whales have other mechanisms for retaining water, it is important to test this group. The finding that whales have small cross-sectional nasal areas would support the contention that there is a correlation between large nasal passages and the presence of nasal turbinates. However, it would disqualify the use of nasal passage-size for diagnosing endothermy, because whales are endothermic. Large nasal passages in whales would vindicate the method of using cross-sectional area to diagnose endothermy, but it would suggest alternative explainations for the correlation between mass-relativearea and endothermy that Ruben et al. (1996) observed.

The following study is an attempt to address this issue by examining the cross-sectional nasal areas of cetaceans. The analysis was performed on the skulls of nine species from four families of Odontoceti (toothed whales). For each animal, measurements were made at several points along the nasal passage, and a single average value was reported. The single average value was log-transformed and compared to the logtransformed mass of the animal. The resulting regression lines were then compared to those obtained by Ruben et al. (1996). The questions asked in this study were whether the cross-sectional area of the nasal passages of a fossil taxon may be used to 
diagnose endothermy and, whether the relationship observed by Ruben et al. (1996) was caused by the presence of nasal turbinates in endotherms and their absence in ectotherms. Since the publication of Ruben et al. (1996), John Ruben has proposed that the cross-sectional area of the nasal passages may be related to resistance to air-flow (Morell 1996). The following study will seek to address this possibility. 


\section{Materials and Methods}

\section{Animals}

Nineteen skulls were examined from nine species representing four families of odontocete cetaceans (Table 1). All of the skulls were from the collection housed at the Portland State University Museum of Vertebrate Zoology.

\section{Casting}

Liquid latex (Mold-It $\left.{ }^{(}\right)$was painted onto the inner surface of the nasal passages with a paintbrush. In order to reduce tears in the latex, at least one layer of either cheesecloth or nylon jerseynetting was pressed into the wet latex and allowed to dry. Each layer of latex was allowed to dry for at least $30 \mathrm{~min}$ before applying successive coats. The last coat of each cast was allowed to dry for at least $12 \mathrm{hr}$ before attempting to release the cast from the skull. Water or talcum powder was applied to the free surfaces, immediately prior to releasing, to prevent the casts from sticking to themselves.

\section{Preparation for Measurement}

Latex casts were prepared for measurement by sectioning the casts into several slices (the number of slices ranged from 3 to 24 , depending on the length and diameter of the cast) and measuring 
the areas of each section. Casts were sliced into rings 0.1 to $2 \mathrm{~cm}$ wide (again, depending on the length and diameter of the cast) with scissors. Care was taken to make each slice approximately normal to the axis of the cast.

Measurement of the composite nasal areas, $A_{n}$ and $A_{m i d}$

The slices of each cast were laid out on a Canon NP6050 ${ }^{\circledR}$ photocopier and photocopied at maximum contrast. The perimeters of the resulting images were then traced into a PICT file on a Macintosh $\mathrm{LCIII}^{(}$computer, using an Acecat $\left.{ }^{(}\right)$graphics tablet and MacDraw $2^{\circledR}$. The area of each slice was then measured by the program, NIH Image v1.59 ${ }^{\complement}$, using the Analyze Particles feature, with the "include interior holes" option checked and the scale set to 53 pixels per $\mathrm{cm}$. A composite nasal area $\left(A_{n}\right)$ was then calculated for each animal by averaging the areas of all the slices in each nostril, and summing the two average areas (right and left) from each animal. According to the equation:

$$
\bar{A}_{n}=\bar{A}_{\text {right }}+\text { Aleft }_{\text {, }}
$$

where $\overline{\mathrm{A}}_{\text {right }}$ and $\overline{\mathrm{A}}_{\text {left, }}$ are the average areas from the right and left 18 
nasal passages of an animal, respectively. An area at the midpoint ( $A_{\text {mid }}$ )was also calculated by summing the areas of the two slices (right and left) closest to the approximate midpoint along the length of the nasal passage.

Owing to their large size, the areas for Physeter macrocephalus were measured by photocopying the sections and then weighing the photocopied images. Seven squares of paper of known areas, ranging from $1 \mathrm{~cm}^{2}$ to $16 \mathrm{~cm}^{2}$ were weighed and used as a standard to convert the mass of the photocopied image into an area.

\section{Shrinkage and Repeatability}

The degree of expected shrinkage was tested by making casts of the inner surfaces of plastic pipes with known diameter. The casts were removed, measured and then remeasured daily over a four-day period.

The nasal passages of one skull were re-measured six times to gauge the precision of the procedure. The last cast made from that skull was then measured daily over the successive three days to test for shrinkage, as above. 


\section{Estimates of Individual Masses.}

Various methods were used to estimate masses.

1) Recorded masses:

Recorded live-weights were available for two of the animals in the study (\#'s 6 and 7). The mass used for each animal was an average mass from over the adult life of the animal.

2) Estimates by age:

One animal (\#2) was assumed to be the same weight as an animal (not included in the study) whose mass was known, because it was approximately the same age.

One animal (\#3) was known to be a young adult. The mass for a young adult of this species, as recorded in the CRC book of Masses (Silva and Downing 1995), was used as an estimate of this animal's mass.

3) Estimates by length:

The masses of animal numbers $10-13,15-18$, and $20-22$ were estimated from linear measurements. Records of body length and maximum girth were available for most of these animals. Regression lines from the literature (Read and Tolley 1997) were used to estimate mass from length and girth or just length, except in the following cases. 
Only the skull-length was available for Physeter macrocephalus (animal \#17). Total body length was estimated by taking the relative skull-to-body proportions from a photograph of a complete skeleton. Mass was then calculated by regression (Omura 1950).

No regression information was available for Stenella longirostris (\#18) and Delphinus delphis (\#20), but mass was estimated by comparison to animals with similar snout to eye distances from Gihr and Pilleri 1969.

The mass of animal \#14 was estimated by comparison of proportions with number 19.

4) Estimates by Volume Calculation:

Volume was used to estimate mass for all animals (\#9, \#19) for which no specific relationship between length and mass was known. Volumes were calculated in segments. The following formulas were derived from basic geometrical relationships. The volumes of the anterior- and posterior-most segments were modeled as simple right-circular cones, with

$$
V=(1 / 3) L C^{2} / 4 \pi
$$


where $\mathrm{L}$ is the height of the cone, and $\mathrm{C}$ is the circumference at the base. Intermediate segments were modeled as truncated segments of cones, with

$$
V=L\left((\pi / 3)\left(r_{2}-r_{1}\right)^{2}+\pi r_{1}\left(r_{2}-r_{1}\right)+\pi r_{1}{ }^{2}\right)
$$

where $r_{2}$ is the larger radius, $r_{1}$ is the smaller radius and $L$ is the length between the two parallel surfaces. Radii were calculated from measured girths. The total number of segments used (including end-segments) was dependent on the number of girths measured for that animal for which there were measured distances between the girths.

The volumes of the flukes and flippers were calculated from length measurements. The volume of the flukes was modeled as an isosceles triangular prism $3 \mathrm{~cm}$ thick. The flippers were modeled as obtuse, scalene triangles, also $3 \mathrm{~cm}$ thick. The sides of the triangles were known. The height, $h$ (in the mathematical sense of a perpendicular to one side), was calculated by the equation:

$$
h=\left(a^{2}-\left(\left(b^{2}-a^{2}-c^{2}\right) / 2 c\right)^{2}\right)^{1 / 2}
$$


where $a$ and $c$ are the short sides of the flipper and $b$ is the longest side (c was always the linear dimension at the base of the flipper). Height could then be used to calculate volume by the formula:

$$
V=(1 / 2) \text { dhc, }
$$

where $d$ is the thickness of the flipper, $h$ is the height defined above, and c (same as c from eq. (4)) is the base of the flipper. Mass was then estimated from the total volume by multiplying by a density of $1 \mathrm{~g} / \mathrm{cc}$.

\section{Analysis}

Several methods were used to analyze the data. Both $\log A_{n}$ and $\log \mathrm{A}_{\text {mid }}$ were regressed against $\log$ body-mass. Differences between $A_{n}$ and $A_{\text {mid }}$ were analyzed by performing a paired t-test between $A_{n}$ and $A_{\text {mid. }}$.

The line obtained by regressing $\log \mathrm{A}_{n}$ against $\log$ body mass was visually compared to the regression line obtained by Ruben et al. (1996) for endotherms. The regression line for ectotherms (Ruben et al 1996) was visually compared to the 95\% confidence interval for $\log A_{n}$ vs. $\log$ body mass, given in the regression model in the GraphPad Prism ${ }^{\odot}$ statistical package.

Because model-I regression assumes great accuracy and 23 
precision in the x-axis, and because the mass-data used in this study were often estimates, it was deemed necessary to examine the effects of this error on the results. In addition to the basic procedure, $\log A_{n}$ was regressed against two other sets of estimated log masses, one representing the smallest possible mass for the animal, and the other representing the largest. The methods by which these minima and maxima were estimated varied according to the method used to arrive at the original value. Values obtained by regression were assumed to be correct to within the margin of error listed in the study from which the relationship was taken. Volume-based estimates were assumed to have error in the density of the animal and minimum and maximum masses were acquired by varying density between 0.97 and $1.08 \mathrm{~g} / \mathrm{cc}$.

Animals whose masses had been measured in life were assumed to have no error in their masses for the purposes of this study.

For the animal (\#2) whose mass was assumed to be the same as that of another animal of similar age and sex, the masses of a slightly older and a slightly younger animal were used to estimate the maximum and minimum respectively. For the animal (\#3) for whom the only available estimates of mass were the reports in the CRC Handbook of Masses, the minimum estimate was the lowest 
mass listed, and the maximum estimate was the largest reasonable mass listed. 


\section{$\underline{\text { Results }}$}

Casts that were allowed to dry overnight before removing from the mold exhibited no shrinkage. All others were excluded from all analyses. The six repeated casts of the same animal had a minimum $A_{n}$ of $39.2 \mathrm{~cm}^{2}$, a maximum $A_{n}$ of $43.2 \mathrm{~cm} 2$, an average of $41.2 \mathrm{~cm}^{2}$ and a standard deviation of $1.6 \mathrm{~cm}^{2}$. This error was considered insignificant; all other areas were measured only once.

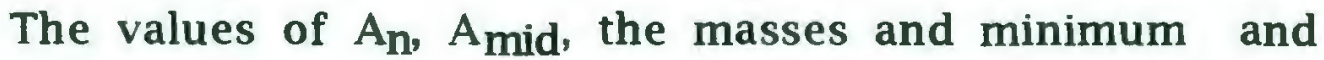
maximum estimates of masses are listed in Table 1. The slope of the regression line of $\log A_{n}$ vs. $\log$ mass was 0.77 and was significantly different from zero (Fig. 1). The slope of the regression of $\log A_{\text {mid }}$ vs. $\log$ mass was 0.77 and was also significantly different from zero. The $y$-intercepts of the two lines ( $A_{n}$ and $A_{\text {mid }}$ ) were both -0.44 . The paired t-test showed that the values of Amid were not significantly different from the values of $A_{n}$ for each animal. The two lines were colinear (Fig. 2). The combined slope was 0.77 and the combined intercept was -0.44 .

Ruben et al.'s (1996) endotherm line lies entirely within the 95\% confidence interval calculated for the cetacean $\log A_{n}$ vs. $\log$ body mass. Their ectotherm line lies outside and below these confidence intervals. Even when the effects of error in the masses of the 26 
animals of this study are taken into account, the line given by Ruben et al. (1996) for endotherms lies between the 95\% confidence intervals of the minimum and maximum lines for $\log A_{n}$ vs. $\log$ mass, and their ectotherm line falls outside these confidence intervals (Fig. 3 a,b). 


\section{$\underline{\text { Discussion }}$}

Ruben et al. (1996) intended to use large nasal cross-sectional area as an indicator of nasal turbinates that had been ablated in the fossil record. However, whales, in general, also have large nasal cross-sectional area, and yet have no nasal turbinates, which argues to the contrary: large nasal cross-sectional nasal area in a fossil does not necessarily indicate the presence of turbinates in the living animal. At best, large nasal cross-sectional area indicates nasal turbinates in an ancestor (if we assume that the last terrestrial ancestor of whales had respiratory turbinates).

The question of whether a large nasal cross-sectional area reliably indicates endothermy is quite different. Bennet and Ruben (1986) required two criteria for a good fossil indicator of a physiological parameter: strong correlation between the indicator and the parameter, and a direct causal link between the indicator and the parameter. None of the birds or mammals studied to date have small nasal cross-sectional area relative to mass, whereas all of the ectotherms so far studied do have a small nasal crosssectional area (Ruben et al. 1996). This association satisfies the requirement laid down by Bennett and Dalzell (1973) for strong 
correlation (although critics might point out that more ectotherms could have been included in the study). If a causal link that does not include turbinates can be established, then the fact that whales have no turbinates will be essentially irrelevant to the question of whether the size of the nasal passages (relative to body mass) indicate metabolic status.

Wide nasal passages have a low air-flow resistance. This argument is appealing because it is a more direct explanation of the observation that endotherms have larger nasal passages than ectotherms do. It is known that for amphibians and suspected that for mammals the ventilatory step is rate-limiting for the expulsion of carbon dioxide at $\mathrm{VO}_{2 \max }$ (Withers and Hillman 1988). To facilitate this process, we would expect an endotherm, with its high resting and activity metabolisms, to have wider nasal passages than an ectotherm of comparable body mass. Poiseuille's law predicts that a small increase in the radius of an airway will cause a large decrease in the resistance of the airway. Poiseuille's law is expressed as:

$$
\mathrm{P}_{1}-\mathrm{P}_{2}=8 \mathrm{Q} \eta \mathrm{L} / \pi \mathrm{r}^{4},
$$

where $P_{1}-P_{2}$ represents a drop in pressure along a tube of length $L$ 
and radius $r$; $Q$ is the rate of flow, and $\eta$ is the viscosity of the fluid. The resistance can be found by combining equation 6 with the series-resistance law,

$$
\mathrm{P}_{1}-\mathrm{P}_{2}=\mathrm{QR} \text {, }
$$

where $\mathrm{R}$ is the resistance to airflow across a distance to get

$$
\mathrm{QR}=8 \mathrm{Q} \eta \mathrm{L} / \pi \mathrm{r}^{4}
$$

The ratio of resistances in the two tubes is

$$
\mathrm{R}_{1} / \mathbf{R}_{2}=\mathrm{r}_{2}{ }^{4} / \mathbf{r}_{1}{ }^{4} .
$$

A porpoise's nasal passages are not perfectly circular, but a single one is typically about $1 \mathrm{~cm}$ in radius (assuming a single, circular nostril), or $3.14 \mathrm{~cm}^{2}$ in area. An ectotherm of similar mass would have a total nasal cross-sectional area of $0.93 \mathrm{~cm}^{2}$ and a nasal radius of $0.54 \mathrm{~cm}$ (Ruben et al. 1996). We can calculate that a porpoise with a nasal cross-sectional area similar to that of an ectotherm of the same mass would have 11 times more resistance in each of its nasal passages than the typical porpoise has. The alternative to increasing the size of the nasal passages would be an 
order of magnitude greater work-load on the respiratory muscles during both high and low activity and/or carbonic acid buildup in the animal's bloodstream during high activity, exactly when it could least be afforded. We would expect small nasal passages only in animals that have low minute volumes. It is conceivable that whales have retained large nasal passages solely by phylogenetic or ontogenetic "inertia," and that there is no functional significance to the width of their nasal passages. However, if the nasal passages had decreased in size during the evolution of this order, they would have to exert much more force to produce the fast "blow" for which they are known.

Further evidence for this resistance-explanation rests in the slopes of the regression lines of this study and studies of metabolism. The slope of the regression line from this study is 0.77 , which is very similar to the slope of the regression line found for log metabolic rate vs. log mass in mammals, 0.776 (Heusner 1982, Hill and Rahimtulla 1965). In the study by Ruben et al. (1996), the slope for endotherms was 0.68. The ectotherms slope in Ruben et al. (1996) was 0.76. All these slopes are statistically indistinguishable. These data suggest that the residuals from the regression of $\log A_{n}$ vs. $\log$ mass might correlate with the residuals of log metabolism vs. log body mass. It seems likely that the size 
of the nasal passages and the rate of metabolism share both a direct causal link and a strong correlation in all species studied so far. If so, the size of the nasal passages is a more direct test of endothermy than the presence of nasal turbinates.

\section{Implications for Ruben et al. (1996)}

The three dinosaurs studied (Ruben et al. 1996) clearly had narrow nasal passages relative to their body mass. Although the masses of these animals must have been estimated, this may not be a great cause for concern. Several of the data points presented here had wide margins of error, but did not adversely affect the placement of the regression line. This is a fortunate consequence of two factors: the logarithmic scale and the great difference in mass between an endotherm and an ectotherm that have the same cross-sectional nasal area. If there is confidence in the crosssectional nasal area, an animal initially placed directly on one line must have half an order of magnitude of uncertainty in its mass before it must be deemed truly closer to the other line.

Another potential problem with the study (Ruben et al. 1996) was the method of measurement. Because the resistance to airflow is inversely related to the fourth power of radius, small changes in the size along the airway may have a large effect on the 
resistance. A single measure of cross sectional area at the central point might miss significant constrictions along the airway. The data in this study show that there was no statistically significant difference between using a single value $\left(A_{\text {mid}}\right)$ and using multiple, averaged values $\left(A_{n}\right)$ for the cross-sectional areas in the species studied. 


\section{Conclusions}

Depite their lack of nasal turbinates, whales have nasal passages as wide as any endotherm of the same mass. It is likely that the size of the nasal passages is set by a need to reduce airflow resistance. This makes the use of nasal cross-sectional area a very direct test of ventilatory rate in fossil animals. Furthermore, error analysis shows that this test is not very sensitive to error in the estimation of mass, which is the principle source of error when dealing with well preserved fossils in this context. 
Table 1. Cross-sectional areas (An) in $\mathrm{cm} 2$, and masses (minimum, maximum and intermediate) in $\mathrm{kg}$.

\begin{tabular}{|l|c|c|c|c|c|c|}
\hline \multicolumn{1}{|c|}{ Species } & ID \# & $\begin{array}{c}\text { An } \\
(\mathrm{cm} 2)\end{array}$ & $\begin{array}{c}\text { Amid } \\
(\mathrm{cm})\end{array}$ & $\begin{array}{c}\text { Mass } \\
(\mathrm{kg})\end{array}$ & $\begin{array}{c}\text { Maximum } \\
\text { mass (kg) }\end{array}$ & $\begin{array}{l}\text { Minimum } \\
\text { mass (kg) }\end{array}$ \\
\hline Delphinus delphis & 20 & 9.19 & 9.77 & 48 & 48 & 46 \\
\hline Globicephala macrorhynchus & 2 & 34.2 & 42.97 & 340 & 386 & 289 \\
\hline Globicephala macrorhynchus & 6 & 36.96 & 16.89 & 340 & 340 & 340 \\
\hline Globicephala macrorhynchus & 7 & 41.98 & 46.96 & 431 & 431 & 431 \\
\hline Kogia simus & 3 & 23.08 & 23.73 & 368 & 417 & 318 \\
\hline Lagenorhynchus obliquidens & 14 & 11.42 & 8.67 & 73 & 79 & 73 \\
\hline Lagenorhynchus obliquidens & 19 & 9.03 & 11.03 & 84 & 91 & 85 \\
\hline Phocoena phocoena & 10 & 5.71 & 6.58 & 53 & 56 & 50 \\
\hline Phocoena phocoena & 12 & 6.24 & & 50 & 53 & 47 \\
\hline Phocoena phocoena & 13 & 5.6 & 4.29 & 36 & 38 & 34 \\
\hline Phocoena phocoena & 15 & 6.36 & 6.75 & 53 & 56 & 50 \\
\hline Phocoena phocoena & 16 & 4.67 & 5.04 & 10 & 11 & 9 \\
\hline Phocoena phocoena & 21 & 7.73 & 8.02 & 81 & 85 & 77 \\
\hline Phocoena phocoena & 22 & 8.19 & 8.19 & 81 & 85 & 77 \\
\hline Phocoena phoconea & 11 & 6.26 & 8.60 & 53 & 56 & 50 \\
\hline Phocoenoides dalli & 9 & 11.2 & 8.03 & 81 & 88 & 82 \\
\hline Physeter catodon & 17 & 250 & 249.6 & 2650 & 6060 & 2440 \\
\hline Stenella longirostris & 18 & 6.49 & 7.34 & 52 & 52 & 50 \\
\hline Tursiops truncatus & 5 & 18.71 & 8.18 & 249 & 299 & 249 \\
\hline
\end{tabular}




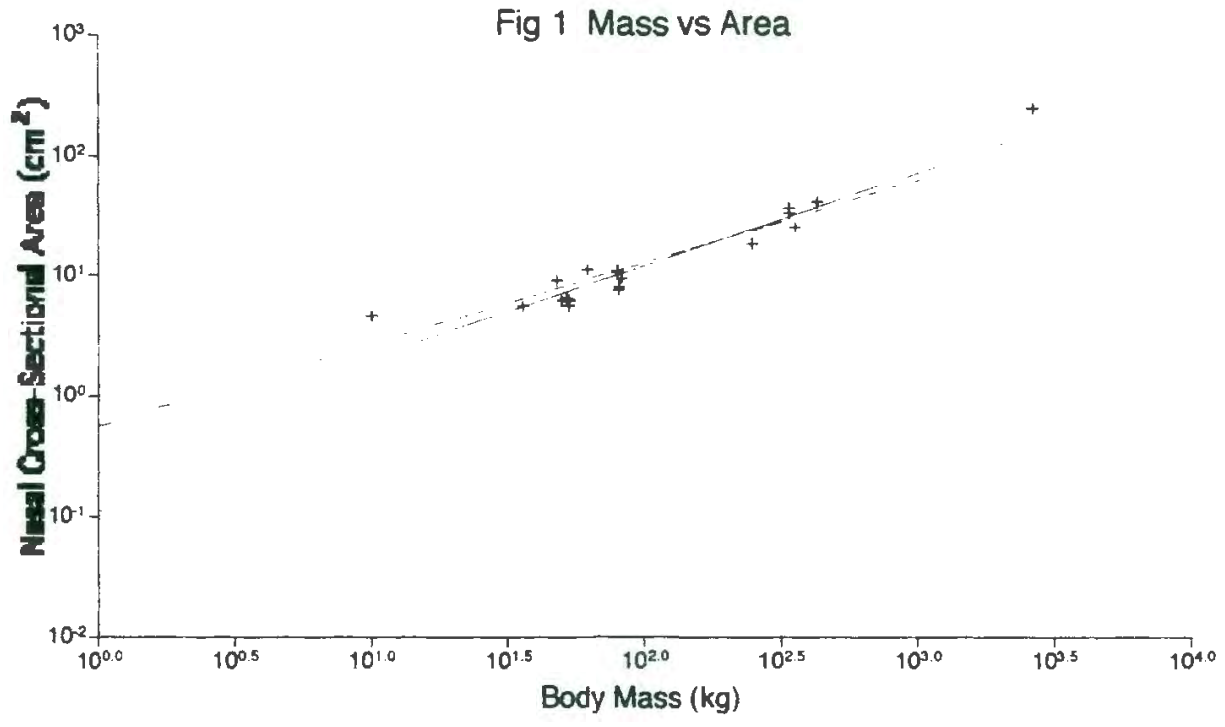

Fig. 1 The regression line of $\log A_{h} v s \log$ body mass, compared to the log cross-sectional area vs log body mass regressions found by Ruben et al. (1996) for endotherms (broken black line) and ectotherms (grey line). $A_{n}=0.36 \mathrm{M}^{77}$

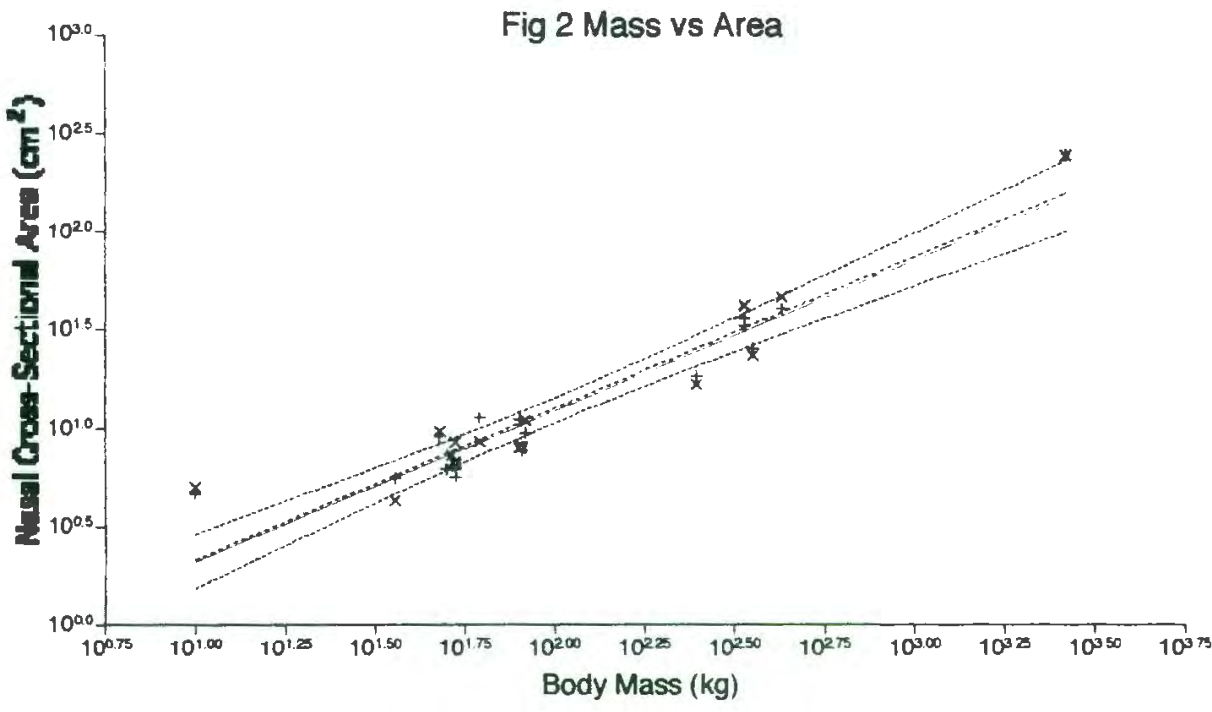

Fig. 2 The regression line of $\log$ A vs log body mass (+-signs, solid line), compared to $\log A_{\text {mid }} v s \log$ body mass ( $X$-signs, broken line). The curved lines represent the $95 \%$ confience interval of the line $\log A_{n} v s \log$ body mass. 
Fig 3a Cross-sectional Area vs Maximum Body Mass

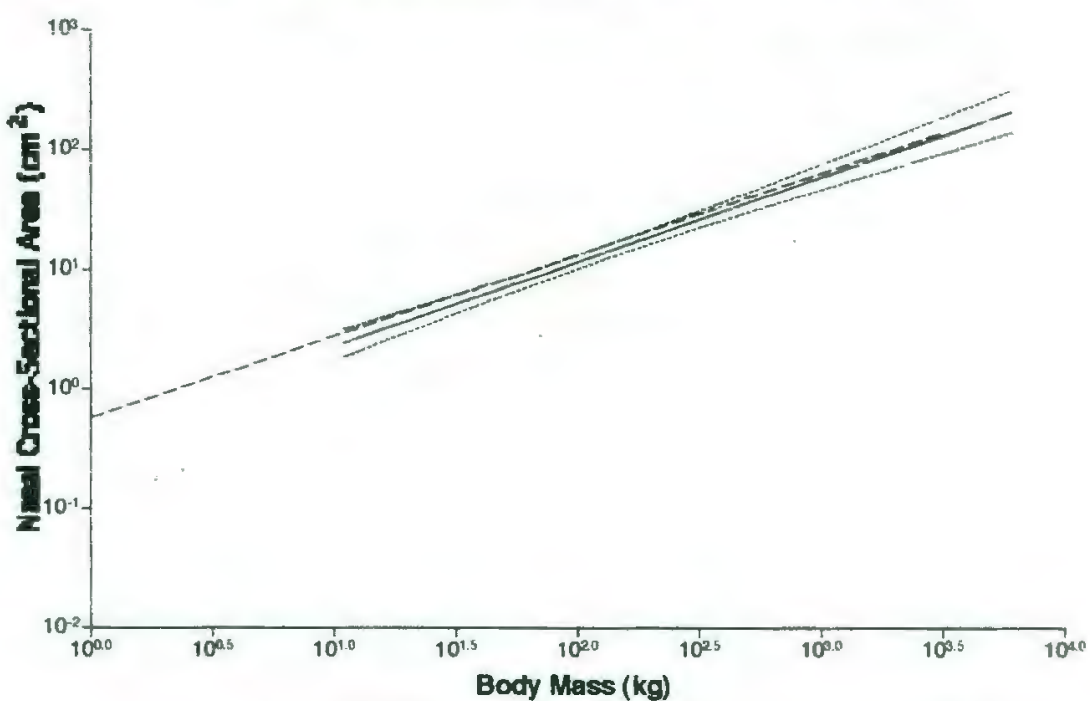

Fig. 3a The regression line of $\log A$ vs. $\log$ maximum mass (solid bleck line) with $95 \%$ confidence interval (solid black cunes), as compared to cross-sectional areavs mass for endotherms (broken black line) and ectotherms (solid grey line) from Ruben et al . 1996.

Fig 3b Cross-sectional Area vs Minimum Body Mass

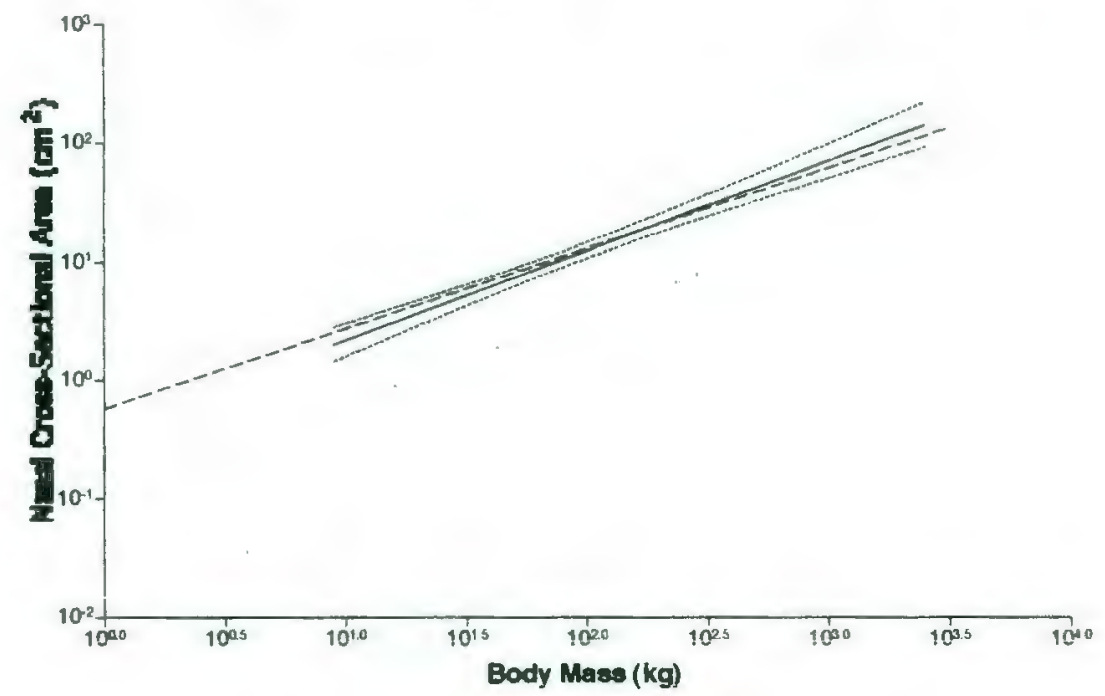

Fig. 3b. The regression line of $\log A$ vs. $\log$ minimum mass (colid black line) with $95 \%$ confidence interval (solid black curves), as compared to croes-sectional areavs mass for endotherms (broken black line) and ectotherms (solid grey line) from Ruben of al. 1996. 


\section{$\underline{\text { Reference List }}$}

Auffenberg, W. 1971. Animal Kingdom 73:19.

Bakker, R. T. 1968. The superiority of dinosaurs. Discovery 3:1122.

Bakker, R. T. 1971. Dinosaur physiology and the origin of mammals. Evolution 25:636-658.

Bakker, R. T. 1972. Anatomical and ecological evidence of endothermy in Dinosaurs. Nature 238:81-85.

Bennett, A. F. and B. Dalzell 1972. Dinosaur Physiology: a Critique. Evolution 27:170-174

Bennett. A. F., and J. A. Ruben. 1986. Endothermy and activity in vertebrates. Science. 206:64-654.

Bouvier, M. 1977. Dinosaur haversian bone and endothermy. Evolution. 31:449-450.

Collins, J. C., T. C. Pilkington, and K. Schmidt-Nielsen. 1971. A model of respiratory heat transfer in a small mammal. Biophysical Journal 11:86-914.

Enlow, D. H. and S. O. Brown. 1957. A compararative histological study of fossil and recent bone tissue. Part II. Texas Journal of Science. 9:186-214.

Enlow, D. H. and S. O. Brown. 1958. A compararative histological 
study of fossil and recent bone tissue. Part III. Texas Journal of Science. 10:187-230.

Feduccia, A. 1973. Dinosaurs as reptiles. Evolution 27:166-169.

Gihr, M. and G. Pilleri. 1969. On the anatomy and biometry of Syenella styx Gray and Delphinus delphis L. (cetacea, delphinidae) of the western mediterranean. in G. Pileri, ed. Investigations on Cetacea. 1:15-65.

Heusner, A. A. 1982. Energy metabolism and body size. I. Is the 0.75 mass exponent of Kleiber's equation a statistical artifact? Respir. Physiol. 48:1-12.

Hill, J. R. and K. A. Rahimtulla. 1965. Heat balance and the metabolic rate of new-born babies in relation to environmental temperature; and the effect of age and weight on basal metabolic rate. Journal or Physiology. 180:239-265.

Hillenius, W. J. 1992. The evolution of nasal turbinates and mammalian endothermy. Paleobiology 18:17-29.

Hillenius, W. J. 1994. Turbinates in therapsids: evidence for Late Permian origins of mammalian endothermy. Evolution 48: 207-229.

Huggins, S. E., H. E. Hoff, and M. E. Valentinuzzi. 1971 Oxygen consumption of small caimens under basal conditions. Physiol. Zool. 44:40-47 
Jackson, D. C. and K. Schmidt-Nielsen. 1964. Countercurrent heat exchange in the respiratory passages. 'Procedings of the national academy of sciences. 51:1192-1197

Negus, V. 1958. Comparative anatomy and physiology of the nose and paranasal sinuses. F. and S. Livingstone, Edinburgh.

Omura, H. 1950. On the body weight of sperm and sei whales located in the adjacent waters of Japan. The Scientific Reports of the Whales Research Institute 4:1-13.

Ostrom J. H. 1969. Terrestrial vertebrates as indicators of mesozoic climates. Proc. North American Paleontological Convention: 347-376.

Read, A. J. and K. A. Tolley. 1997. Postnatal growth and allometry of harbour porpoises from the Bay of Fundy. Canadian Journal of Zoology 75:122-130.

Reid, R. E. H. 1987. Bone and dinosaurian "endothermy". Modern Geology 11:133-154.

Ricqles, A. J. de.1974. Evolution of endothermy: histologial evidence. Evolut. Theory. 1:51-80.

Romer, A. S. and T. S. Parsons. 1986. The vertebrate body, 6th ed. Saunders College, Philadelphia.

Ruben, J. A., W. J. Hillenius, N. R. Geist, A. Leitch, T. D. Jones, P. J. Currie, J. R. Horner, and G. Espe III. 1996. The metabolic 
status of some Late Cretaceous dinosaurs. Science. 273:1204-1207.

Russel, L. S. 1965. Body temperature of dinosaurs and its relationship to their extinction. J. Paleontology, 39:497-501.

Schaller, G. B. 1968. Hunting behavior of the cheetah in the Serengeti National Park, Tanzania [Acinonyx jubatus]. East African Wildlife Journal 6:95-100.

Schmidt-Neilsen, K. 1969. The neglected interface: the biology of water as a liquid-gas system. Quarterly Review of Biophysiology 2:283-304.

Schmidt-Neilsen, K. 1972. Recent advances in the comparative physiology of desert animals.Pp. 371-382 in G.M.O. Maloiy, ed Comaparative physiology of desert animals. Symposium of the Zoological Society of London.

Schmidt-Neilsen, K., R. C. Schroter, and A. Shkolnik. 1981.

Desaturation of exhaled air in camels. Procedings of the Royal Society of London B211:305-319.

Schroter, R. C., and N. V. Watkins. 1989. Respiratory heat exchange in mammals. Respiration Physiology 78:357-368.

Schroter, R. C., D. Robertshaw, M. A. Baker, V. H. Shoemaker, R. Holmes, and K. Schmidt-Nielsen. 1987. Respiration in heat stressed camels. Respiration Physiology. 70: 97-112. 
Silva, M. and J. A. Downing. 1995. CRC Handbook of Mammalian Body Masses. CRC Press. Boca Raton.

Spotila, J. R., P. W. Lommen, P. S. Bakken and D. M. Gates. 1973. A mathematical model for for body tempertaures of large reptiles: implications for dinosaur ecology. Am Nat. 107:391404.

Thulborn, R. A. 1973. Thermoregulation in dinosaurs. Nature. 245:51-52.

Walker, J. E. C., R. E. Wells, and E. W. Merrill. 1961. Heat and water exchange in the respiratory tract. American Journal of Medicine. 30:259-267.

Withers. P. C. and S. S. Hillman. 1988. A steady-state model of maximal oxygen and carbon-dioxide transport in anuran amphibians. Journal of Applied Physiology 64:860-868.

Witmer, L. M. 1995. Homology of facial structures in extant archosaurs (birds and crocodilians), with special reference to oranasal pneumaticity and nasal conchae. Journal of Morphology. 225:269-327.

Wright, B. S. 1960. Predation on big game in East Africa. Journal of Wildlife Management 24:1-15. 